\title{
EXODONTIA ATRAUMÁTICA COM USO DE EXTRATOR DENTÁRIO E INSTALAÇÃO IMEDIATA DE IMPLANTE EM REGIÃO ANTERIOR DA MAXILA
}

\begin{abstract}
Thiago de Almeida Prado Naves Carneiro*, Mário Duílio Evaristo Henry Neto**, Nícolas Vasconcellos André***, Ana Cristina Peres Magalhães****
\end{abstract}

Autor correspondente: Thiago de Almeida Prado Naves Carneiro - E-mail: tapncarneiro@hotmail.com

* CD, mestre e doutorando em Odontologia pela Faculdade de Odontologia - Universidade Federal de Uberlândia - FO/

UFU. Professor do Instituto de Pesquisa, Extensão e Ensino Odontológico

** CD, mestre e especialista em Cirurgia e Traumatologia Bucomaxilofacial, Especialista em Implantodontia (FOUFU-MG).

Diretor e Professor do Instituto de Pesquisa, Extensão e Ensino Odontológico

*** CD, especialista em Implantodontia e Prótese Dentária. Professor do Instituto de Pesquisa, Extensão e Ensino Odontológico

**** CD, mestre em Reabilitação Oral (FOUFU-MG). Diretora e Professora do Instituto de Pesquisa, Extensão e Ensino Odontológico

\section{Resumo}

Novas técnicas reabilitadoras protéticas têm sido desenvolvidas no intuito de diminuir o tempo de tratamento, assim como o custo e o trauma cirúrgico dos pacientes. Além disso, minimizam agravos psicológicos, principalmente em regiões com envolvimento estético. A Instalação imediata de implantes já e uma realidade e estudos clínicos têm demonstrado que a taxa de sucesso dos implantes imediatos é similar a dos implantes instalados após o reparo ósseo. O objetivo deste trabalho é apresentar um caso clínico de instalação de um implante em substituição imediata após a exodontia atraumática, através do uso do extrator radicular Neodent. Implantes imediatos em carga imediata, quando corretamente indicados, são uma alternativa rápida e segura para a reabilitação de dentes condenados, pois permitem a preservação da arquitetura óssea, além de proporcionar ao paciente um menor número de cirurgias e consequentemente menor morbidade, além de proporcionar ao paciente conforto psicológico e satisfação estética e funcional imediata.

Palavras-chave: Implantes dentários; Prótese dentária fixada por implante; Procedimentos cirúrgicos minimamente invasivos. 


\title{
ATRAUMATIC EXTRACTION USING DENTAL EXTRACTOR AND IMMEDIATE IMPLANT PLACEMENT IN THE ANTERIOR REGION OF THE MAXILA
}

\begin{abstract}
New techniques have been developed in order to reduce the time of treatment, minimizing the cost and the psychological and surgical trauma of the patients, especially in regions with aesthetic involvement. The immediate placement of dental implants is a reality and clinical studies have shown that the success rate of immediate implant is similar to that placed after bone repair. The objective of this study is to present a clinical case of a immediate implant placement to substitute a central incisor after atraumatic extraction, through the use of Neodent root extractor. Immediate implant placement and immediate loading, when correctly indicated, are a quick and safe alternative for the rehabilitation of affected teeth, they also allow the preservation of bone architecture, and provides the patient a lower number of surgeries and consequently less morbidity. It also promotes psychological comfort, immediate aesthetic and functional satisfaction to the patient.
\end{abstract}

Keywords: dental implants; Implant-Supported Dental Prosthesis; Minimally Invasive Surgical Procedures.

\section{INTRODUÇÃO}

Atualmente, os tratamentos odontológicos reabilitadores têm passado por diversas mudanças e na implantodontia não poderia ser diferente. No intuito de minimizar o tempo e o custo do tratamento, além de diminuir o trauma cirúrgico e psicológico dos pacientes com necessidades de próteses implantadas, novas técnicas foram propostas e têm se mostrado bastante promissoras e com taxas de sucesso compatíveis às técnicas convencionais. A Instalação imediata de implantes já e uma realidade, e a técnica consiste na remoção de um elemento dentário e instalação imediata de um implante no alvéolo ainda fresco. A técnica cirúrgica preconizada não realiza incisões ou descolamentos mucoperiosteais, mantendo a vascularização do osso vestibular, minimizando sua reabsorção e preservando as papilas interdentais. Essa técnica permite à diminuição do tempo de espera pela prótese definitiva, menor número de intervenções cirúrgicas, eliminação da utilização de prótese provisória removível, favorece a manutenção dos tecidos periimplantares, além de oferecer um relativo conforto psicológico ao paciente. Fraturas radiculares causadas pelo trauma ou pela presença de pinos intrarradiculares sem as proporções adequadas, lesões periapicais refratárias ao tratamento endodôntico, bem como a doença periodontal, são alguns fatores que podem levar à perda dentária. Essa perda provoca importantes alterações estéticas, especialmente quando há comprometimento dos tecidos ósseo e gengival da região anterior da maxila e da mandíbula.(1)

Estudos clínicos têm demonstrado que a taxa de sucesso dos implantes imediatos é similar a dos implantes instalados após o reparo ósseo. ${ }^{(2-5)}$ Evidências científicas demonstram que a implantação imediata preserva a arquitetura alveolar e favorece a manutenção da altura das cristas ósseas, ${ }^{(6,7)}$ assim, a manutenção do contorno e da espessura gengival é favorecida, fatores essenciais para uma 
estética final do caso. O objetivo deste trabalho é apresentar um caso clínico de instalação de um implante em substituição imediata após a exodontia atraumática através do uso do extrator radicular Neodent e discutir as vantagens desta técnica.

\section{RELATO DE CASO}

Paciente sexo masculino, 35 anos de idade, feoderma, procurou atendimento apresentando prótese fixa no incisivo central superior direito desadaptada com alteração de cor. Ao exame físico, observou-se prótese fixa metalocerâmica e núcleo metálico no dente 11 com posição ligeiramente vestibularizada, alteração de cor e presença de fístula crônica e profundidade de sondagem vestibular de $5 \mathrm{~mm}$. Para complementação diagnóstica solicitou-se os seguintes exames de imagens: Radiografia periapical (Figura 1, Apêndice) e radiografia panorâmica e Tomografia Computadorizada Cone Been 3D da região (Figuras $1 \mathrm{~B}$ e $1 \mathrm{C}$, Apêndice). Os cortes tomográficos apresentaram o dente $11 \mathrm{com}$ tratamento endodôntico, presença de núcleo intra-canal fora das proporções ideais e coroa protética; osteólise na região radicular periapical (cortes transversais $n^{\circ} 69$ e 70) e linha radiolúscida na face vestibular radicular em terços cervical e apical (cortes $n^{\circ} 7$ e 72). Diante das evidências clínicas e radiográficas verificou-se a impossibilidade de tratamento conservador e manutenção dental.

$\mathrm{Na}$ história médica pregressa e atual não apresentou alterações sistêmicas relevantes que possam interferir no tratamento. $O$ tratamento de eleição foi a exodontia atraumática utilizando o Extrator Dentário (Neodent ${ }^{\circledR}$, Curitiba-Brasil) com a seguinte técnica preconizada: incisão sulcular com lâmina de bisturi $n^{\circ} 11$ prévia à instalação do tracionador no interior da raiz dentária (Figura 2, Apêndice). Depois, é realizado o preparo do canal dentário com broca helicoidal de $1.3 \mathrm{~mm}$ para extrator sob irrigação abundante e fixação do tracionador no interior da raiz dentária, com auxílio da chave digital. A remoção da raiz se dá por meio do giro do manípulo, no sentido horário observando a manuten- ção do longo eixo do cabo em relação a raiz dentária (Figura 3, Apêndice A).

Imediatamente após a exodontia (Figura 4, Apêndice), realizou-se a curetagem e inspeção alveolar e instrumentação do leito receptor para receber o implante e instalação imediata do implante Alvim CM de corpo cônico com junção protética do tipo cone morse com seguinte diâmetro e plataforma $4.3 \times 16.00 \mathrm{~mm}$ Neodent ${ }^{\circledR}$. Foi utilizado como protocolo de fresagem a sequência de brocas recomendadas pelo fabricante: Lança, Broca Alvim 2.0, Broca Alvim 3.5, Broca Alvim 4.3 e em seguida a instalação do implante (Figura 5, Apêndice). O posicionamento tridimensional do implante foi $3 \mathrm{~mm}$ abaixo do centro da gengiva marginal vestibular, centralizado em relação ao espaço mésio-distal e vestíbulo-palatal, com emergência na borda incisal para confecção de prótese cimentada. Como a estabilidade primária do implante superou 45 Newtons de torque optou-se pela reabilitação protética provisória imediata. O pilar para confecção da prótese foi selecionado através do Kit de Seleção Protética Cone Morse Neodent ${ }^{\circledR}$; o componente protético escolhido foi o Munhão Universal CM reto em corpo único $4.5 \times 6 \times 1.5$, em seguida confeccionou-se o provisório sobre o cilindro do munhão universal através de dente de estoque.

Após 6 meses, o perfil gengival havia sido mantido e foi realizada a restauração final em cerâmica feldspática (Figura 6, Apêndice). Após 24 meses de proservação, observa-se um ótimo resultado clínico com preservação papilar e manutenção da gengiva marginal, o paciente relata estar satisfeito com resultado estético e funcional obtido pela reabilitação.

\section{DISCUSSÃO}

A substituição dentária imediata oferece excelentes resultados, estudos clínicos têm demonstrado que a taxa de sucesso dos implantes imediatos é similar a dos implantes instalados após o reparo ósseo. (1-8) A utilização de implantes de junção interna representa uma excelente opção para preservação da 
estética nesses casos, por oferecer manutenção da altura das cristas ósseas e do contorno gengival. ${ }^{(9)} A$ exodontia deve ser realizada da maneira mais atraumática possível, a técnica cirúrgica preconizada não realiza incisões ou descolamentos mucoperiosteais, mantendo a vascularização do osso vestibular, minimizando sua reabsorção e preservando as papilas interdentais. Neste caso, foi utilizado o Extrator Dentário (Neodent, Curitiba-Brasil). O tracionador no interior do conduto radicular permite a remoção de raiz por meio de tração através do giro do manípulo, o que evita o uso de instrumentos diretamente sobre a tábua óssea. A presença de infecção e inflamação associadas aos dentes a serem substituídos não tem disso considerada como uma contra indicação para instalação imediata de implantes, deve-se tomar o cuidado de realizar adequada curetagem do alvéolo, removendo todo o tecido de granulação, associada ao uso de clorexidina o,12\% para lavagem do alvéolo. ${ }^{(9)}$

A utilização de implantes de junção interna do tipo Morse representa uma excelente opção, por oferecer maior manutenção da altura das cristas ósseas favorecendo a manutenção da arquitetura gengival.(10) O implante selecionado para o caso foi um implante do tipo Alvim, um implante cônico, de junção Morse que proporciona excelente estabilidade primária. $\mathrm{Na}$ região anterior de maxila, devido a sua anatomia, em casos unitários, é preferível a utilização de próteses cimentadas, pois facilitam a higienização devido ao fato de o implante seguir o longo eixo do dente que existia naquela posição originalmente, assim, não se faz necessária nenhuma compensação vestibular. É importante salientar que o uso de guias cirúrgicos é de fundamental importância tanto no planejamento quanto na execução da instalação cirúrgica, especialmente nos casos de substituição imediata. Sendo assim, a instrumentação do leito receptor foi realizada seguindo o longo eixo da raiz do dente em questão, buscando ancoragem no osso palatino do alvéolo fresco.

Para alcançar um resultado clinico satisfatório é importante seguir um planejamento que inclui observar a qualidade e quantidade óssea, analisar os dentes antagonistas e a presença ou não de hábitos parafuncionais, além de definir a melhor técnica para a exodontia e o implante mais indicado. Além disso, é muito importante que o paciente colabore na manutenção do procedimento, alimentando-se de acordo com as recomendações pós-operatórias e higienizando bem a área em questão para evitar qualquer espécie de infecção.

\section{CONSIDERAÇÕES FINAIS}

Implantes imediatos em carga imediata, quando corretamente indicados, são uma alternativa rápida e segura para a reabilitação de dentes condenados, pois permitem a preservação da arquitetura óssea, além de proporcionar ao paciente um menor numero de cirurgias e consequentemente menor morbidade dentro do período de tempo de espera pela prótese definitiva, que é também minimizado devido ao fato de não se esperar o tempo de reparação alveolar para a instalação do implante dentário, além de proporcionar ao paciente conforto psicológico e satisfação estética e funcional imediata.

\section{REFERÊNCIAS}

1. Donati M, La Scala V, Di Raimondo R, Speroni $S$, Testi M, Berglundh T. Marginal Bone Preservation in Single-Tooth Replacement: A 5-Year Prospective Clinical Multicenter Study. Clin Implant Dent Relat Res. 2013 Jul 24.

2. Romanos G, Froum S, Hery C, Cho SC, Tarnow D. Survival rate of immediately vs delayed loaded implants: analysis of the current literature. J Oral Implantol. 2010; 36(4):315-24.

3. Deng $F$, Zhang $H$, Zhang $H$, Shao $H$, He $Q$, Zhang P. A Comparison of Clinical Outcomes for Implants Placed in Fresh Extraction Sockets Versus Healed Sites in Periodontally Compromised Patients: A 1-Year Follow-up Report. Int J Oral Maxillofac Implants. 2010; 25(5):1036-40.

4. Esposito M, Grusovin MG, Polyzos IP, Felice P, Worthington $\mathrm{HV}$. Interventions for replacing missing teeth: dental implants in fresh extraction 
sockets (immediate, immediate-delayed and delayed implants). Cochrane Database Syst Rev. 2010;8:9-12.

5. McAllister BS, Cherry JE, Kolinski ML, Parrish KD, Pumphrey DW, Schroering RL. Two-year evaluation of a variable-thread tapered implant in extraction sites with immediate temporization: a multicenter clinical trial. Int J Oral Maxillofac Implants. 2012;27(3):611-8.

6. Denissen HW, Kalk W, Veldhuis HA, van Waas MA. Anatomic consideration for preventive implantation. Int J Oral Maxillofac Implants 1993;8(2):191-6.

7. Truninger TC, Philipp AO, Siegenthaler DW, Roos M, Hämmerle CH, Jung RE. A prospective, controlled clinical trial evaluating the clinical and radiological outcome after 3 years of immediately placed implants in sockets exhibiting periapical pathology. Clin Oral Implants Res. 2011;22(1):20-7.

8. Mangano FG, Mangano C, Ricci M, Sammons RL, Shibli JA, Piattelli A. Esthetic evaluation of single-tooth Morse taper connection implants placed in fresh extraction sockets or healed sites. J Oral Implantol. 2013;39(2):172-81.

9. Chrcanovic BR, Martins MD, Wennerberg A. Immediate Placement of Implants into Infected Sites: A Systematic Review. Clin Implant Dent Relat Res. 2013.

1O. Pieri F, Aldini NN, Marchetti C, Corinaldesi G. Influence of implant-abutment interface design on bone and soft tissue levels around immediately placed and restored single-tooth implants: a randomized controlled clinical trial. Int J Oral Maxillofac Implants. 2011;26(1):169-78.

\section{APÊNDICE}

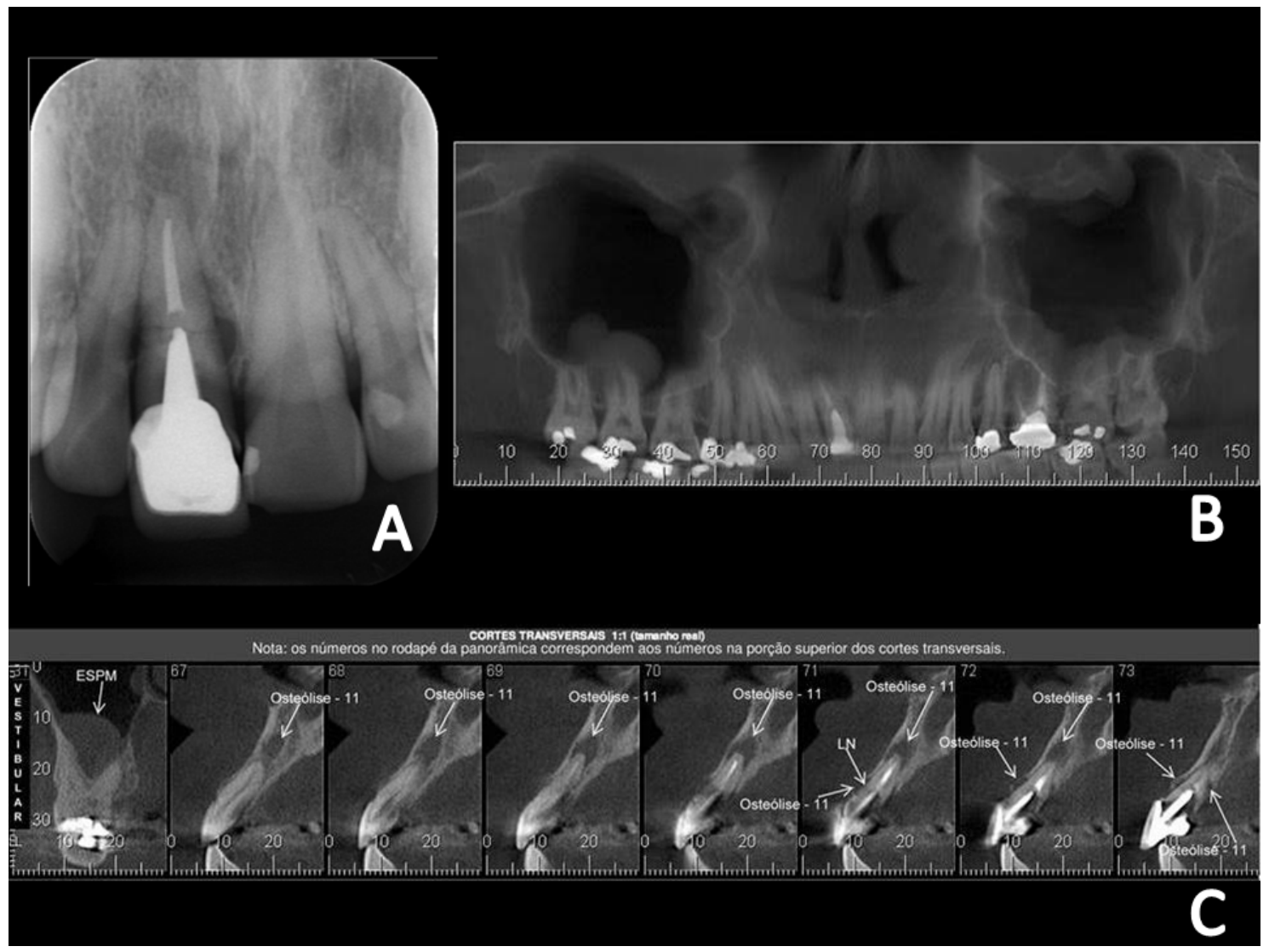

Figura 1 - Radiografia periapical (figura 1A) e radiografia panorâmica e Tomografia Computadorizada Cone Been 3D da região (figura $1 \mathrm{~B}$ e $1 \mathrm{C}$ ). 


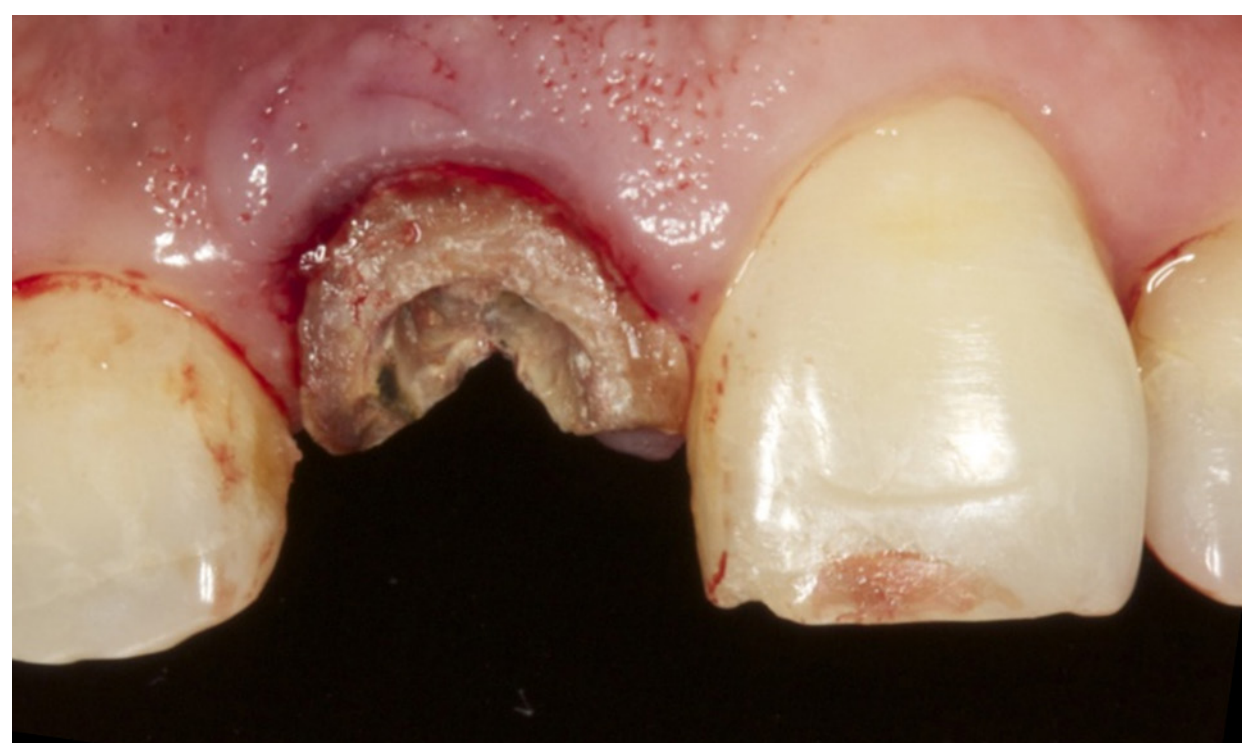

Figura 2 - Remanescente dental após remoção do núcleo intra canal e coroa protética

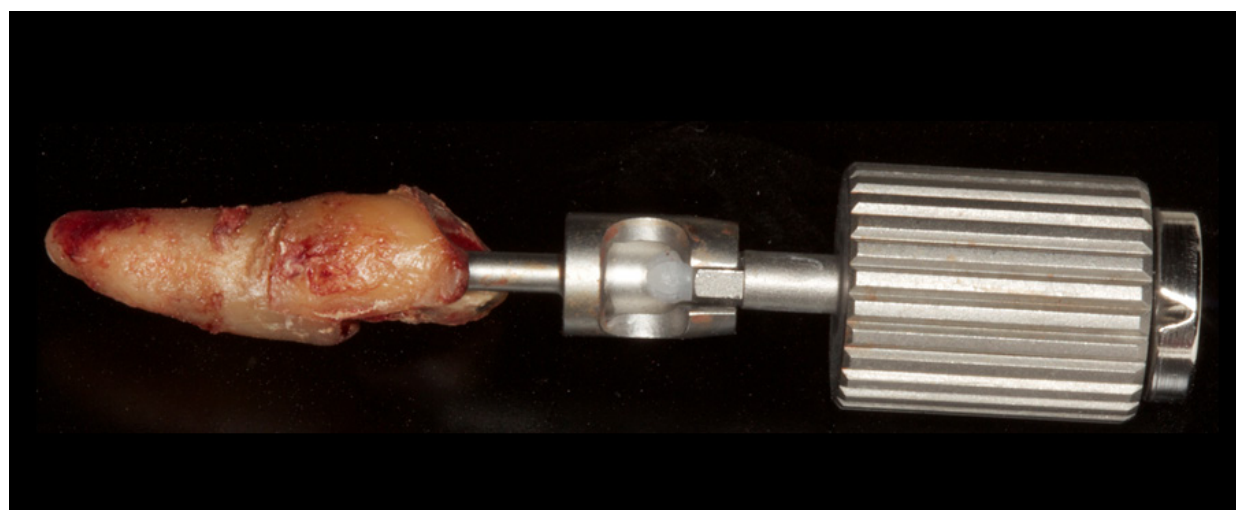

Figura 3 - Raiz dentária do incisivo central superior presa à chave digital do extrator dentário após exodontia atraumática.

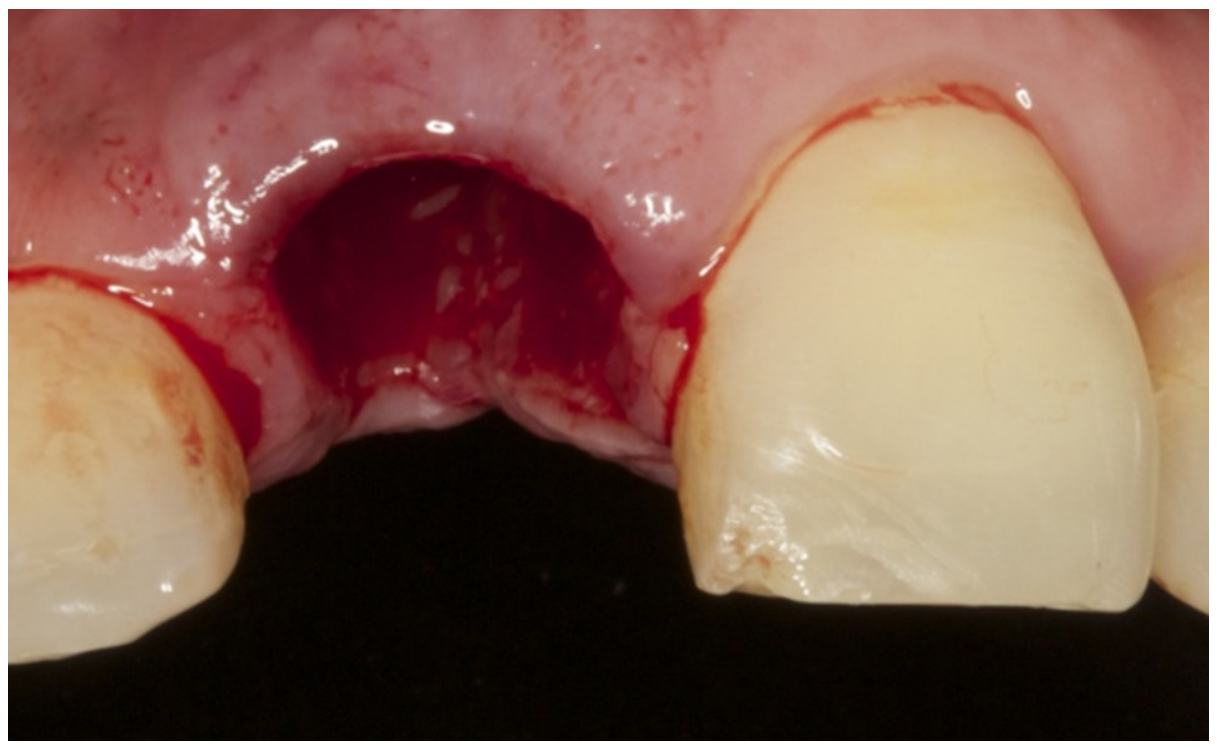

Figura 4 - Alvéolo fresco com preservação da arquitetura óssea e manutenção do tecido mole após a exodontia do remanescente dental. 


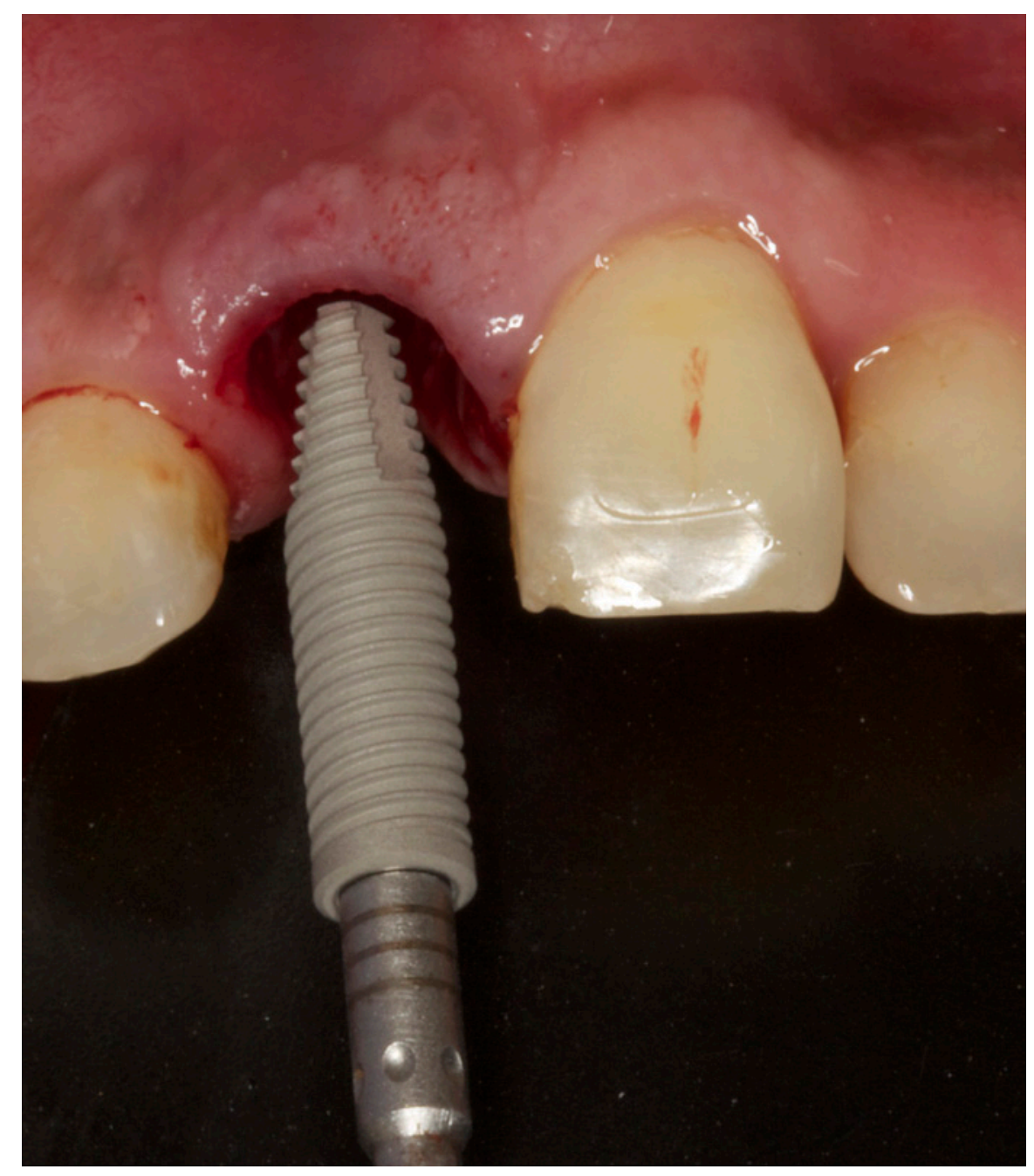

Figura 5 - Instalação do implante Alvim CM de corpo cônico com conexão protética do tipo cone morse 4.3x16.00 mm (Neodent, Curitiba-PR-Brasil).

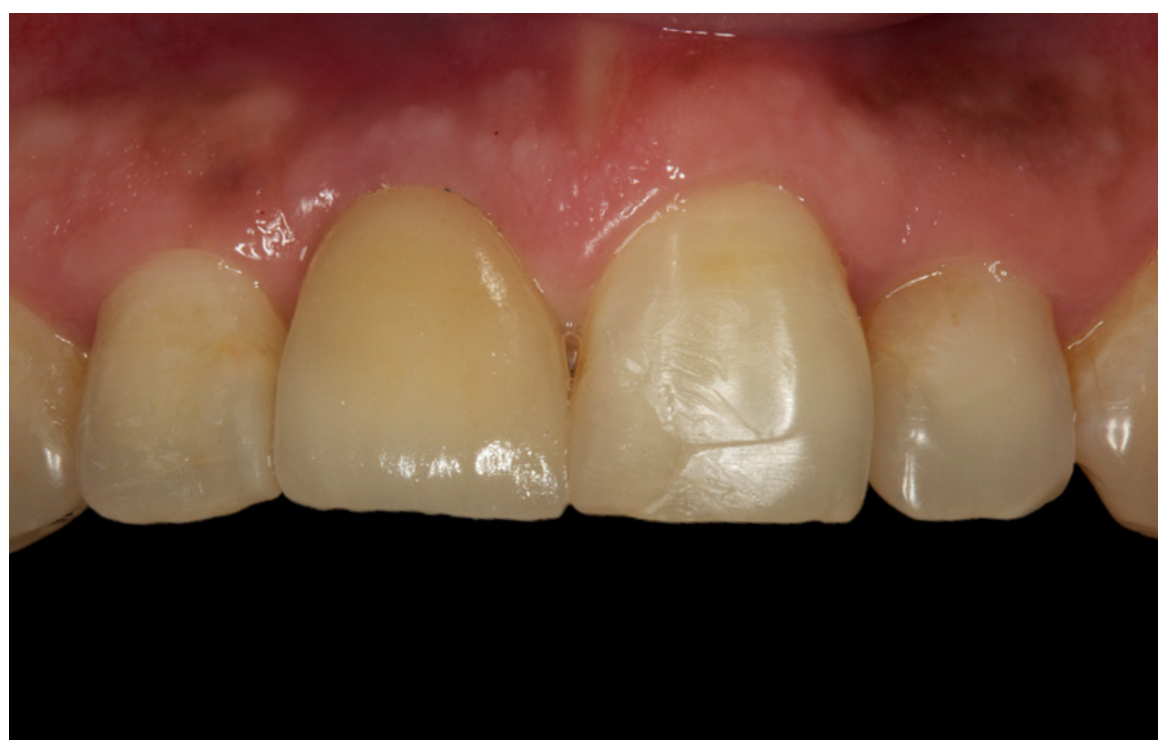

Figura 6 - Restauração final em cerâmica feldspática. 